\title{
Analysis of Ophthalmic Plastic Procedures in a Tertiary Centre
}

\author{
Olusola Joseph Omotoye*, Iyiade Adeseye Ajayi and Funmilola Esther Kumolalo \\ Department of Ophthalmology, Ekiti State University Teaching Hospital, Ado Ekiti, Nigeria; \\ layoshol@yahoo.com, iyiseye2005@gmail.com, funmikumolalo@gmail.com
}

\begin{abstract}
Orbito-oculoplastics diseases and deformities tend to impact negatively on the psycho-social, economic as well as the educational achievement of affected persons. Ophthalmic plastic procedures are performed to improve the appearance and function of the eyelids and face of the affected person. Purpose: To determine the prevalence and indications of oculoplastic procedures in oculopastic subspecialty in order to provide data base for management of ophthalmic plastic conditions in our centre. Method: The clinic and theatre records of all patients that had oculoplastic procedures done from January 2015 - July 2017 were retrieved to obtain demographic characteristics, duration of symptoms, presenting visual acuity and oculoplastic procedures and histo-pathological diagnosis from the records. Results: One hundred and eighty (180) patients had oculo-plastic surgery. This constituted (12.1\%) of all surgeries done in this centre. There were 95(52.8\%) males and $85(48.2 \%)$ females with a male to female ratio of $1.1: 1$. Conjunctival disorders $106(58.9 \%)$ were the most frequent with two third occurring at 40 years and above. This was followed by disorders arising from trauma with greater than $2 / 3$ occurring at younger age group. Most of the ophthalmic cosmetic procedures were performed in the elderly females while the destructive procedures resulting from trauma were performed in the young males. Conclusion: The incidence of ophthalmic plastic procedure was low. There is need fortraining of more staff with adequate and relevant skill in more advance cosmetic oculoplastic surgery and provisioh of up to date equipments required for various procedures in order to improve the practice of this subspecialty in this centre.
\end{abstract}

Keywords: Ophthalmic, Oculoplastic, Procedures, Subspecialty

\section{Introduction}

The eyes otherwise referred to as the "window to the soul" reveal so much about a person's personality, feelings, mood, overall general appearance and self image ${ }^{1}$.Any deformity or disorder around the eye and orbit can negatively impact on the psychosocial, economic as well as educational achievement of affected persons ${ }^{2}$. Apart from the concerns about the function of the eyes, individuals also have great concerns about their cosmetic appearance ${ }^{3}$. The Ophthalmic plastic surgeons assist patients to restore youthfulness around the eyes and orbit in terms of function and appearance ${ }^{4}$. Following the establishment of an Ophthalmic plastic unit in our centre after the completion of the required training by a specialist eye doctor, this study has been carried out to determine how much of these procedures have been done after 3 years as well as the indications. The findings from this study will form a database for ophthalmic plastic conditions in our centre.

\section{Materials and Methods}

One hundred and eighty (180) patients with ophthalmic plastic conditions of all age groups, both male and female in our centre were derived from either self referral, General Ophthalmology Clinics within the centre or other centres within and outside the state. The clinic and theatre records

\footnotetext{
* Author for correspondence
} 
of all patients who had Oculoplastic procedures between January 2015 and July 2017 were retrieved. All patients were examined by the oculoplastic surgeon following referral from ophthalmologists from other subspecialty (Retina, Glaucoma and general ophthalmology clinics) after which clinical diagnoses were made. Demographic characteristics, duration of symptoms, presenting visual acuity, oculoplastic procedures and histo-pathological diagnosis were obtained from the records. Visual acuity were categorized with $\geq 6 / 18$ as normal, $<6 / 18$ to $>3 / 60$ as visual impairment and $<3 / 60$ as blindness. Infants were classified as either blind or believed not to be blind. Ethical approval was obtained from the institution's ethical review committee though data collection did not directly involve patient's participation. Data obtained were recorded and analysed using Statiscal Package for Social Sciences (SPSS) version 20. Means (Standard deviations) were used to describe the distributions of continuous variables. Categorical variables were described in Percentages. Comparisons of categorical data were performed with the use of Pearson's chi-square test. $P<0.05$ was considered statistically significant.

\section{Results}

One hundred and eighty (180) patients had oculo-plastic surgery during this period. This constituted $(12.1 \%)$ of all surgeries $(1,493)$ done in this centre. There were $95(52.8 \%)$ males and $85(48.2 \%)$ females with a male to female ratio of 1.1:1. The ages ranged from 7 months to 81 years with mean age of $41.45 \pm 20.67$ years.

Table 1. Age and sex distribution

\begin{tabular}{ccc}
\hline AGE (YRS) & MALE (\%) & FEMALE (\%) \\
\hline $0-9$ & $14(82.4)$ & $3(17.6)$ \\
$10-19$ & $10(76.9)$ & $3(23.1)$ \\
$20-29$ & $12(63.2)$ & $7(36.8)$ \\
$30-39$ & $10(29.4)$ & $24(70.6)$ \\
$40-49$ & $19(59.4)$ & $13(40.6)$ \\
$50-59$ & $12(54.5)$ & $10(45.5)$ \\
$\geq 60$ & $18(41.9)$ & $25(58.1)$ \\
\hline TOTAL & $95(52.8)$ & $85(56.7)$ \\
\hline
\end{tabular}

The proportions of males were significantly higher in all age groups except at age group 30-39 years and $\geq 60$ years. The majority of patients 97(53.9\%) were 40 years and above $(\mathrm{x} 2=19.920, \mathrm{df}=6, p=0.003)$.
Table 2. Oculoplastic diseases according to age

\begin{tabular}{lccc}
\hline Oculoplastic diseases & $\begin{array}{c}<40 \text { years } \\
(\%)\end{array}$ & $\begin{array}{c}\geq 40 \text { years } \\
(\%)\end{array}$ & $\begin{array}{c}\text { Total } \\
(\%)\end{array}$ \\
\hline Lid disorders & $2(20)$ & $8(80)$ & $10(5.6)$ \\
Trauma & $29(67.4)$ & $14(32.6)$ & $43(23.9)$ \\
Conjunctival lesions & $40(37.7)$ & $66(62.3)$ & $106(58.9)$ \\
Infection/Inflammatory & $4(40)$ & $6(60)$ & $10(5.6)$ \\
Retinoblastoma & $3(100)$ & $0(0)$ & $3(1.6)$ \\
Orbital tumours & $4(66.7)$ & $2(33.3)$ & $6(3.3)$ \\
Lacrimal disorders & $1(50)$ & $1(50)$ & $2(1.1)$ \\
\hline
\end{tabular}

Conjunctival disorders 106(58.9\%) were the most frequent with two third occurring at 40 years and above. This was followed by disorders arising from trauma with greater than $2 / 3$ occurring at younger age group. All cases of retinal lesions occurred at less than 40 years age group.

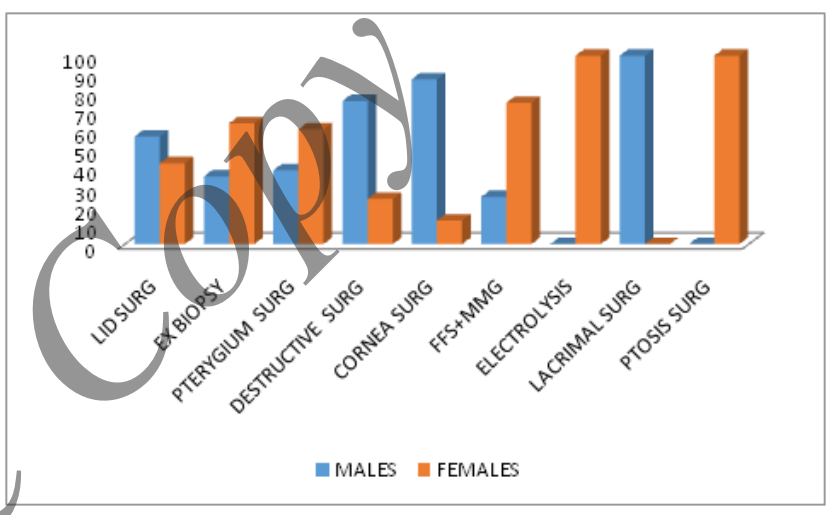

Figure 1. Ophthalmic plastic procedures according to gender.

FFS-Fornix Foramation Suture, MMG-Mucous Membrane Graft

Most of the procedures (Pterygium, FFS + MMG, Electrolysis and Ptosis) were performed in the females while the destructive procedures, corneal repair and lid surgery resulting from trauma were performed in males.

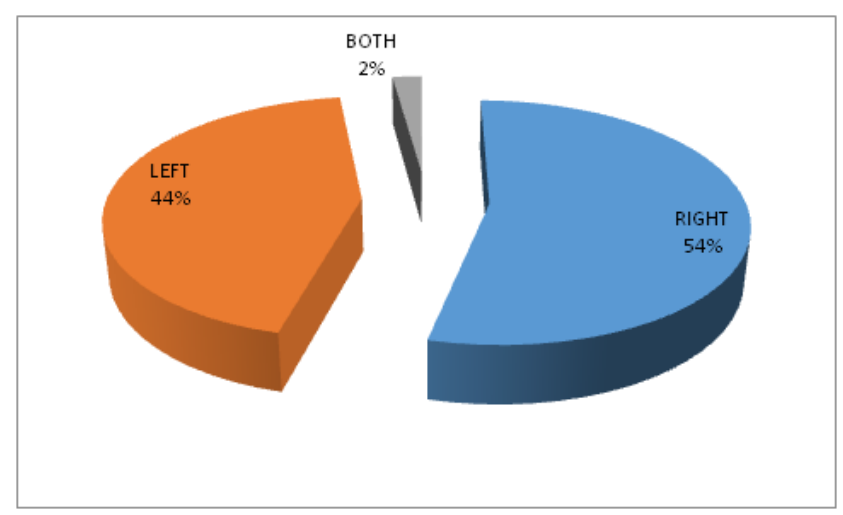

Figure 2. Laterality of surgical procedures. 
The procedure done was unilateral in 176(97.8\%) eyes with $97(53.9 \%)$ of the cases done for the right eye.

\section{Discussion}

The ophthalmic plastic procedures done for the various orbito-ocular diseases in this study constituted $12.1 \%$ of all ophthalmic surgeries done in this centre. This is much lower than $60.6 \%$ of all minor ophthalmic plastic procedures recorded in Northern part of the country ${ }^{1}$. However their study covered seven years period and involved all minor procedures like incision and curettage which were excluded in this study ${ }^{1}$. Many other studies reported the incidence of various individual procedures ${ }^{2,5-7}$. The low incidence could be because of the young age of the oculoplastic subspecialty with limited available facilities. There was a significant male preponderance which is contrary to a study done in another centre of the same geographical location of the country ${ }^{2}$. More males tend to access eye facility than their female counterparts because of reasons like financial prowess of men. Women on the other hand have limited freedom due to their engrossment in domestic ${ }^{8}$ even though it is a known fact that females are more sensitive to the imposed cosmetic disfigurement arising from oculoplastic disorders ${ }^{2}$. Majority of the patients were 40years and above, this might be due to a large contribution of conditions like degenerative eye diseases affecting the elderly ${ }^{6}$. Conjunctival disorders were the most frequent with Pterygium as the leading etiological cause. This was contrary to a report from ahother study at the same geographical location of the country where eyelid diseases was the commonest ${ }^{2}$. Two third of the cases were 40 years and above. Pterygium is a degenerative disease of the bulbar conjunctival tissue which progressively encroaches on the cornea in a triangular fashion. Increasing age have been reported to be one of the independent risk factors in pterygium presentation? Pterygium apart from constituting threat to vision by encroachment into the visual axis can also constitute a cosmetic blemish. Other conjunctival disorders included Ocular Surface Squamous Neoplasia (OSSN)which is the third most common ocular tumor in adults ${ }^{10}$. Few cases of symblepharon, pyogenic granuloma were documented. Moreover, trauma ranked second common estaetiologcal causes of orbito-ocular diseases occurring in young individual of less than 40 years in this study as more young males were involved in activities that can result in severe facial injury ${ }^{11-13}$. This was similar to a study in Lagos where trauma was the leading aetiological factors causing severe facial injury ${ }^{2}$. Few cases of Retinoblastoma were seen in this study. Retinoblastoma is the most common malignant intraocular tumour in children ${ }^{14}$. This is similar to some other studies in Nigeria ${ }^{14}$. However no single case of retinoblastoma was reported by Balogun et al., in her study of orbito-ocular diseases in Lagos ${ }^{2}$. Most of the ophthalmic cosmetic procedures (Pterygium, FFS+MMG, Electrolysis and Ptosis) were performed in the females while the destructive procedures resulting from trauma were performed in the males similar to some authors ${ }^{6,15}$. The methods done for pterygium were pterygium excision with intra operative application of 5 Fluoro Uracil and excision with autograft in order to prevent recurrence. The destructive procedures performed were evisceration with or without orbital implant, enucleation with orbital implant and insertion of conformer and later fixing ocular prosthesis and deepening of orbital socket from previously contracted socket. Norris et al., reported that Madagascan ophthalmic practitioners centre their attention on enucleation, evisceration, and exenteration for presumed traumatic and neoplastic causes ${ }^{16}$ and most common causes for eye removal in African countries are both trauma and orbito-ocular tumours ${ }^{15}$. This is not different from our findings in this centre. In addition, some patients with infections/inflammatory causes resulting in painful blindness had evisceration performed on them and they are to have secondary orbital implant after the infection has been curtailed.

All patients with clinical diagnosis of OSSN had excisional biopsy with Alcohol Kerato Epitheliectomy (AKET) using standard oculopastic procedure of no touch technique and wide excision margin of 3-4 $\mathrm{mm}$. Only few patients had bilateral procedure done on the same day.

\section{Conclusion}

The incidence of ophthalmic procedure was low;most of the ophthalmic cosmetic procedures were performed in the elderly females while the destructive procedures resulting from trauma were performed in the young males. A lot more procedures can still be done in this oculoplastic subspecialty. In order to improve the oculoplastic practice, there is need for training of more 
staff with adequate and relevant skill in more advance cosmetic oculoplastic surgery and provision of up to date equipments required for various procedures.

\section{References}

1. Odugbo O, Mpyet C, Wade P, Adenuga O, Adejoh M. An audit of minor ophthalmic surgical interventions in a tertiary eye care facility in Northern Nigeria. Journal of the West African College of Surgeons. 2014; 4(2):26. PMid:26587521 PMCid:PMC4500769

2. Balogun BG, Adekoya BJ, Balogun MM, Ehikhamen OA. Orbito-oculoplastic diseases in lagos: a 4-year prospective study. Middle East African Journal of Ophthalmology. 2014; 21(3):236. Crossref PMid:25100908 PMCid:PMC4123276

3. Coday MP, Warner MA, Jahrling KV, Rubin PA. Acquired monocular vision: Functional consequences from the patient's perspective. Ophthalmic Plastic and Reconstructive Surgery. 2002; 18(1):56-63. Crossref PMid:11910326

4. Rankin M, Borah GL. Perceived functional impact of abnormal facial appearance. Plastic and reconstructive surgery. 2003; 111(7):2140-6. Crossref PMid:12794453

5. Bukhari A. Etiology of tearing in patients seen in an oculoplastic clinic in Saudi Arabia. Middle East African Journal of ophthalmology. 2013; 20(3):198. Crossref PMid:24014980 PMCid:PMC3757626

6. Muhammad AD, Muhammad N. Indications for destructive eye surgeries in Sokoto, North Western Nigeria. Sudanese Journal of Ophthalmology. 2015; 7(2):41. Crossref

7. Eze BI. Audit of ophthalmic surgical interventions in a resource-deficient tertiary eye care facility in Sub-Saharan Africa. Journal of Health Care for the Poor and Underserved. 2013; 24(1):197-205. Crossref PMid:233777728

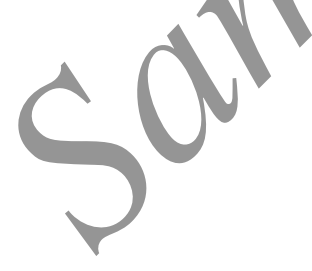

8. Melese M, Alemayehu W, Friedlander E, Courtright P. Indirect costs associated with accessing eye care services as a barrier to service use in Ethiopia. Tropical Medicine and International Health. 2004; 9(3):426-31. Crossref PMid:14996373

9. McCarty CA, Fu CL, Taylor HR. Epidemiology of pterygium in Victoria, Australia. British Journal of Ophthalmology. 2000; 84(3):289-92. Crossref PMid:10684840 PMCid:PMC1723391

10. Simbiri KO, Murakami M, Feldman M, Steenhoff AP, Nkomazana O, Bisson G, et al. Multiple oncogenic viruses identified in Ocular surface squamous neoplasia in HIV1 patients. Infectious Agents and Cancer. 2010; 5(1):6. Crossref PMid:20346104 PMCid:PMC2859758

11. Hashemi H, Khabazkhoob M, Mohammad K, Fotouhi A. History of ocular trauma in tehran population: Tehran eye study. Iranian Journal of Ophthalmology. 2011; 23(3):43-9.

12. Jahangir T, Butt NH, Hamza U, Tayyab H, Jahangir S. Pattern of presentation and factors leading to ocular trauma. Pak J Ophthalmol. 2011; 27(2):96-102.

13. Ajayi IA, Ajite KO, Omotoye OJ. Epidemiological survey of traumaticeye injury in a Southwestern Nigeria tertiary hospital. Pakistan Journal of Ophthalmology. 2014; 30(3):138.

14. Onwubuya IM, Owoyele TM, Olaofe OO, Ezike KN. Morphological spectrum of orbitoocular diseases in a tertiary health centre in Keffi, North Central Nigeria. Advances in Medicine. 2015; 2015.

15. Adeoye A, Onakpoya O. Indication for eye removal in IleIfe, Nigeria. African Journal of Medicine and Medical Sciences. 2007; 36(4):371-5. PMid:18564655

16. Norris J, Gale R, Nkumbe H, Backhouse O, Bernadin P, Chang B. Oculoplastic surgery in Madagascar: A review. Community Eye Health. 2009; 22(70):S3. PMid:19888361 PMCid:PMC2767128 